\title{
A novel therapeutic anti-CD55 monoclonal antibody inhibits the proliferation and metastasis of colorectal cancer cells
}

\author{
SO HEE DHO ${ }^{1,2}$, EUN HA CHO ${ }^{1}$, JI YEON LEE ${ }^{2}$, SO-YOUNG LEE ${ }^{1}$, \\ SUNG HEE JUNG ${ }^{1}$, LARK KYUN KIM ${ }^{2}$ and JAE CHEONG LIM ${ }^{1}$ \\ ${ }^{1}$ Radioisotope Research Division, Department of Research Reactor Utilization, \\ Korea Atomic Energy Research Institute, Daejeon 34057; ${ }^{2}$ Severance Biomedical Science Institute \\ and BK21 PLUS Project for Medical Sciences, Gangnam Severance Hospital, \\ Yonsei University College of Medicine, Seoul 06230, Republic of Korea
}

Received March 15, 2019; Accepted July 26, 2019

DOI: $10.3892 /$ or.2019.7337

\begin{abstract}
In recent years, efforts to treat cancer by improving the immune function of patients have received a great deal of attention. As part of the immune system, complement is also under such evaluation. Among the many components of the complement system, complement decay accelerating factor (CD55 or DAF) is known to inhibit complement-mediated cell lysis. However, little is known about the role of CD55 in terms of cancer therapy. The present study aimed to demonstrate that increased levels of CD55 are strongly correlated with the progression of colorectal cancer. A novel CD55 chimeric monoclonal antibody was developed that may boost the immune response, thereby suppressing cancer. The CD55 antibody treatment activated complement and therefore suppressed the proliferation, invasion and migration of colorectal cancer cells. This tumoricidal activity is partly explained by the inflammatory response via the activation of proinflammatory cytokines. In addition, the CD55 antibody treatment synergistically enhanced the tumoricidal activity of 5-FU in colorectal cancer cells, suggesting that combined treatment may be a better strategy in colorectal cancer therapy.
\end{abstract}

Correspondence to: Dr Lark Kyun Kim, Severance Biomedical Science Institute and BK21 PLUS Project for Medical Sciences, Gangnam Severance Hospital, Yonsei University College of Medicine, Eonju-ro 63-gil 20, Gangnam-gu, Seoul 06230, Republic of Korea

E-mail:1kkim@yuhs.ac

Dr Jae Cheong Lim, Radioisotope Research Division, Department of Research Reactor Utilization, Korea Atomic Energy Research Institute, Daejeon 34057, Republic of Korea

E-mail: limjc@kaeri.re.kr

Key words: CD55, monoclonal antibody, colorectal cancer, complement, immunotherapy

\section{Introduction}

Cancer immunotherapy has been suggested as a new generation of antineoplastic strategies, especially after the great success of $\mathrm{T}$ cell modulatory therapies $(1,2)$. Complement-mediated immunotherapy as well as $\mathrm{T}$ cell immunotherapy can be a target of antineoplastic strategies (3). There is some evidence that complement is an effector mechanism in tumor immunotherapy (3), therapeutic antitumor monoclonal antibodies, including atumumab and rituximab $(4,5)$, and several anticancer drugs, including paclitaxel (6) and cisplatin (7), lead to the activation of complement-dependent cytotoxicity.

Among complement regulatory proteins, the present study focused on decay-accelerating factor (CD55 or DAF or 791Tgp72), an inhibitor of complement-mediated lysis $(8,9)$. A murine monoclonal antibody recognizing 791 Tgp72 has been suggested as a potential therapeutic agent by stimulating T-cell responses (10). A ${ }^{177} \mathrm{Lu}-\mathrm{DTPA}-\mathrm{anti}-\mathrm{CD} 55$ antibody was developed targeting the pleural cavity in pleural metastatic mouse models, suggesting both diagnostic and therapeutic roles for malignant pleural effusion (11). However, the efficacy of the novel anti-CD55 chimeric monoclonal antibody and its inhibition of CD55 on colorectal cancer were not carefully studied. In fact, even the level of CD55 expression in colorectal cancer is not well established (12). Therefore, the levels of CD55 were assessed using tissues from colon cancer patients and studied the role of the new chimeric CD55 antibody in the remission of colorectal cancer.

Colorectal cancer is the third most prevalent cancer affecting both men and women worldwide (13). Colorectal cancer is divided into groups of patients with microsatellite-unstable and microsatellite-stable tumors (14). The former tumors contain many gene mutations and may lead to new immunogenic antigens that provoke immune responses. Indeed, tumors that contain many mutations demonstrate better clinical benefit from immune checkpoint blockade with pembrolizumab than do microsatellite-stable tumors (15). Notably, in contrast to other cancer types, colorectal cancer has shown low efficacy to pembrolizumab (16). Therefore, it was hypothesized that colorectal cancers with many mutations 
may have better outcomes in response to CD55 blockade, which is related to the immune system.

The discovery of 5-fluorouracil (5-FU) in 1957 was a landmark advance for patients with colorectal cancer and has since been used as one of the first-line treatments in advanced colorectal cancer (17). However, 5-FU is mainly limited due to its resistance (18). Therefore, combination therapies, such as FOLFOX (5-FU, leucovorin, and oxaliplatin), FOLFIRI (5-FU, leucovorin, and irinotecan), FLOT (5-FU, oxaliplatin, and docetaxel), and ECF (epirubicin, cisplatin, and 5-FU), have been established as efficacious cytotoxic regimens (19). Notably, these regimens are further combined with a monoclonal antibody, such as cetuximab and bevacizumab, according to the molecular characteristics $(19,20)$.

The aim of the present study was to validate a novel anti-CD55 antibody as an effective therapy for managing colorectal cancer. Herein, it is demonstrated that anti-CD55 is a promising therapeutic agent as both a monotherapy and a combined therapy with 5-FU in colorectal cancer.

\section{Materials and methods}

Selection of CD55-specific scFvs and preparation of anti-CD55 $\operatorname{IgG}$. Construction of a naïve chicken phage-displayed $\mathrm{scFv}$ library, biopanning to select CD55-specific scFvs, and preparation of anti-CD55 IgG were performed by SG Medical, Inc., as previously described (11). Flow cytometric analysis was used to validate the anti-CD55 antibodies and CD55-expressing colorectal cancer cell lines. CD55-positive cells were stained with an Alexa Fluor 647 (A-20186; Molecular Probes; Thermo Fisher Scientific, Inc.)-conjugated anti-CD55 antibody and measured by a BD FACS Canto II. The anti-CD55 Ab except for the IHC (AP14798A; Abgent, Inc.) and immunoblotting (ab54595; Abcam) is not commercially available. The sequence of the antibody is also not publicly available because patent application is in progress.

Cell culture.HT-29(ATCC HTB-38), DLD-1 (ATCC CCL-221), SW-620, HCT-15 (ATCC CCL-225), and LoVo (ATCC CCL-229) colorectal cancer cells and THP-1 (ATCC TIB-202) monocytes were maintained in RPMI-1640 (11875119; Gibco; Thermo Fisher Scientific, Inc.) with $10 \%$ FBS. Mutation data were obtained from the Sanger Institute (21), according to which LoVo cells contain somatic mutations in KRAS, MSH2, APC, and FBXW7 genes. Cells were preincubated with $100 \mu \mathrm{M}$ of 5-FU (F6627; Sigma-Aldrich; Merck KGaA) for $1 \mathrm{~h}$ prior to incubation with $100 \mu \mathrm{g} / \mathrm{ml}$ anti-CD55 antibody unless otherwise indicated.

C5a release. DLD-1 or SW-620 cells were incubated in the presence of human complement (S1764; Sigma-Aldrich; Merck KGaA). Cell supernatants in triplicate of standards and samples containing $100 \mu \mathrm{g} / \mathrm{ml}$ chimeric anti-CD55 antibody or human $\mathrm{IgG}$ were assayed for C5a using a commercial human C5a ELISA kit (HK349; Hycult Biotech). C5a release was quantified using a microplate reader at $450 \mathrm{~nm}$.

Reverse transcription-quantitative PCR (RT-qPCR) of cytokines. The effect of anti-CD55 antibody on cytokine production in THP-1 cells was measured by RT-qPCR. THP-1 cells were pretreated with or without anti-CD55 (100 ng/ml) or control IgG $(100 \mathrm{ng} / \mathrm{ml})$ for $1 \mathrm{~h}$ and then stimulated for $3 \mathrm{~h}$ with LPS $(1 \mu \mathrm{g} / \mathrm{ml}$, tlrl-peklps; Invivogen; Thermo Fisher Scientific, Inc.). Total RNA was isolated with TRIzol Reagent (15596026; Ambion; Thermo Fisher Scientific, Inc.) according to the protocol of the manufacturer. For RT-qPCR, cDNA was synthesized from $2 \mu \mathrm{g}$ of total RNA using oligo dT and SuperScript Reverse Transcriptase IV (18090050; Invitrogen; Thermo Fisher Scientific, Inc.) in accordance with the protocol of the manufacturer. The cDNA was amplified with a set of gene-specific primers and SYBR Green (4309155; Invitrogen; Thermo Fisher Scientific, Inc.) and then subjected to RT-qPCR quantification using the Light Cycler 480 II (Roche Diagnostics). The thermocycling conditions were as follows: Pre-denaturation at $95^{\circ} \mathrm{C}$ for $5 \mathrm{~min}$ followed by denaturation at $95^{\circ} \mathrm{C}$ for $10 \mathrm{sec}, 60^{\circ} \mathrm{C}$ annealing for $10 \mathrm{sec}$ and $72^{\circ} \mathrm{C}$ extension for $10 \mathrm{sec}$, for 45 cycles; finally denaturation occurred at $95^{\circ} \mathrm{C}$ for $5 \mathrm{sec}$ and $65^{\circ} \mathrm{C}$ for $1 \mathrm{~min}$. Gene expression was normalized to that of GAPDH. RT-qPCR primer sequences are listed in Table I.

Statistical analysis. Statistical analysis for each of the experiments (Figs. 2 and 3) was determined by Student's t-test. For the comparison of multiple groups (Fig. 4C and D) the one-way analysis of variance (ANOVA) followed by Tukey's post hoc test, a method that takes into account the repeated measurements, was appropriate instead of the t-test (23). $\mathrm{P}<0.05$ was considered significant. In addition, cancer outlier profile analysis (COPA) of CD55 was applied to the GENT database (http://medical-genome.kribb.re.kr /GENT/) using the Affymetrix U133A and U133Plus2 platforms (22) (Fig. 1A and B). Supporting materials and methods are presented in Data S1.

\section{Results}

Upregulation of CD55 during tumor progression of colorectal cancer. CD55 mRNA was overexpressed in subsets of colorectal cancer tissues rather than across all colorectal cancer cases (Fig. 1A and B). To validate the CD55 mRNA overexpression in colorectal cancer tissues, immunohistochemical analysis was performed in 62 samples. Of the 41 colorectal adenocarcinoma tissues, 21 (51.2\%) were strongly positive for CD55 (Table SI). Strong CD55 expression was not observed in Stage I colorectal cancer (Table SII). CD55 was strongly positive in the later clinical stages of colorectal cancer. CD55 was expressed on cell membranes and in the cytoplasm, particularly in differentiated colon adenocarcinoma (Fig. 1C). This suggests that the overexpression of CD55 is required in the progressive stage of colorectal cancer but not in the early stage of colorectal cancer.

Validation of a novel chimeric anti-CD55 monoclonal antibody. To validate CD55 as a target of colorectal cancer, a novel chimeric human anti-CD55 monoclonal antibodies constructed from phage-displayed antibody fragments was developed. In the present study, the focus for novel anti-CD55 monoclonal antibodies was the specific targeting of colorectal cancer cells expressing CD55. HT-29 and SW-620 colorectal cancer cells were used as positive (outlier) and negative 
Table I. Primers used for reverse transcription-quantitative PCR.

\begin{tabular}{llc}
\hline Target & Forward $\left(5^{\prime}-3 '\right)$ & Reverse $\left(5^{\prime}-3^{\prime}\right)$ \\
\hline Human TNF & CAGGGAGCCTTTGGTTCTGG & CCGTGTCTCAAGGAAGTCTGG \\
Human IL-6 & TCTGCGCAGCTTTAAGGAGT & CCCAGTGGACAGGTTTCTGA \\
Human IL-1 $\beta$ & CCATCAGCCAGGACAGTCAG & TCAGGCGGGCTTTAAGTGAG \\
Human GAPDH & AATCCCATCACCATCTTCCA & TGGACTCCACGACGTACTCA
\end{tabular}

\section{A}

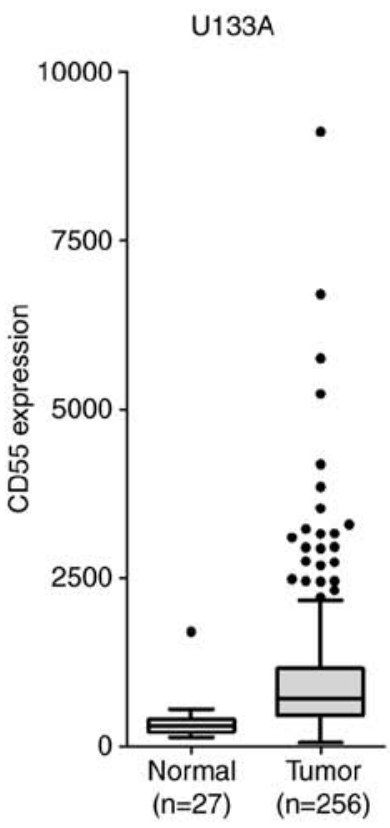

C
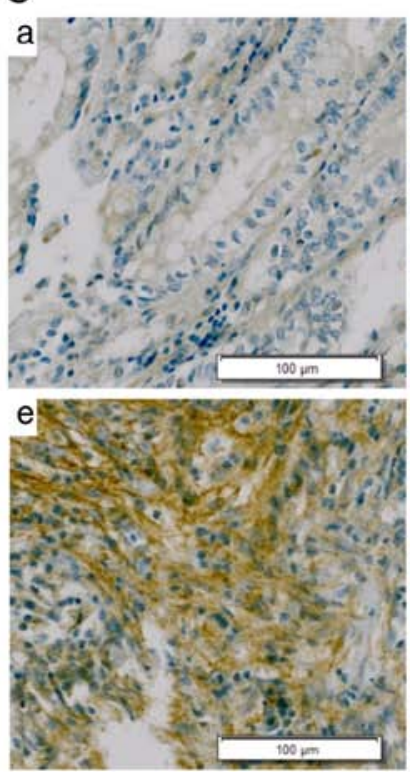
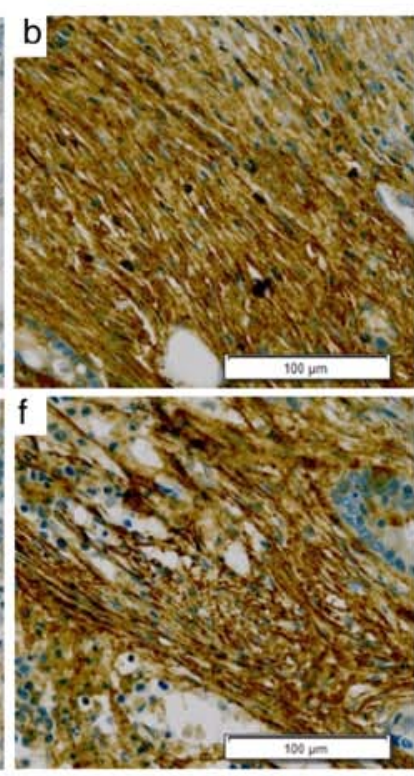

B

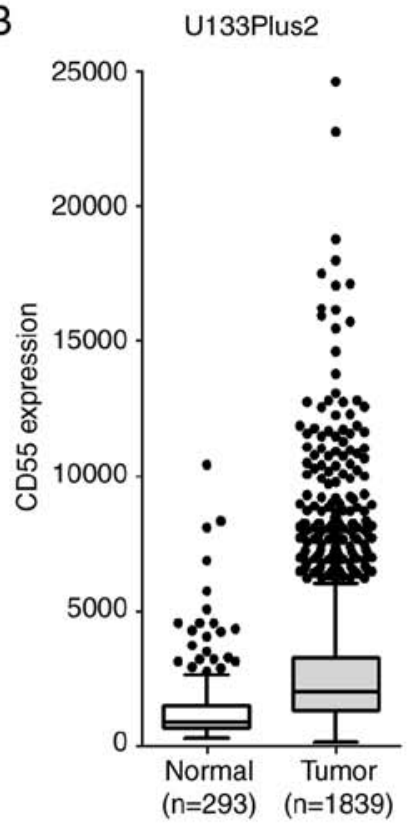

Figure 1. Expression of CD55 in colorectal cancer tissues. (A) CD55 mRNA expression in normal colon and colorectal cancer tissues using the Affymetrix U133A platform. (B) CD55 mRNA expression in normal colon and colorectal cancer tissues using the Affymetrix U133Plus2 platform. Expression was assessed using the GENT database. Boxes indicate the 75th percentile, median and 25th percentile. Dots indicate outliers. (C) Immunohistochemical analysis of CD55 in colon tissues. (a) Normal colon rectum; (b) rectum adenocarcinoma, well differentiated; (c) sigmoid colon adenocarcinoma, well differentiated; (d) transverse colon adenocarcinoma, moderately differentiated; (e) cecum adenocarcinoma, moderately differentiated; (f) ascending colon adenocarcinoma; (g) rectum mucinous adenocarcinoma; (h) descending colon mucinous adenocarcinoma. Scale bars, $100 \mu \mathrm{m}$.

(nonoutlier) controls, respectively. Notably, only the Ab1 anti-CD55 antibody specifically bound to HT-29 cells by flow cytometry among the strong possible candidates (Fig. 2A). This result suggests that the Ab1 anti-CD55 antibody (herein 
A
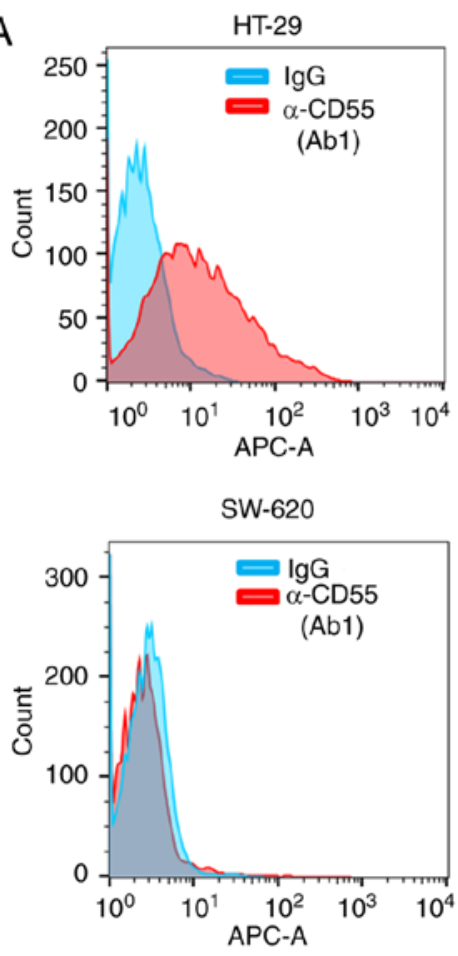

B

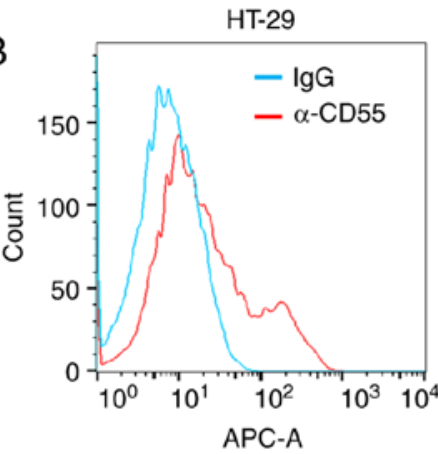

DLD-1

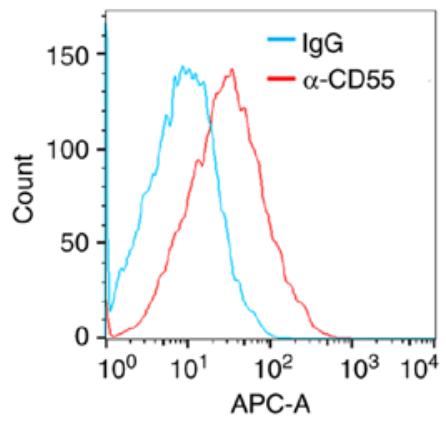

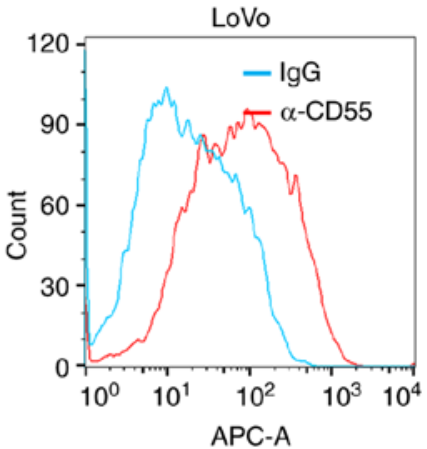

SW620

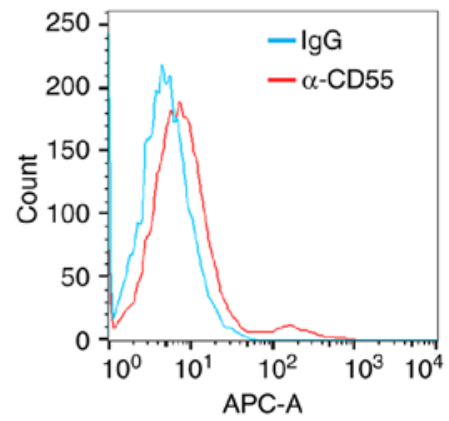

C
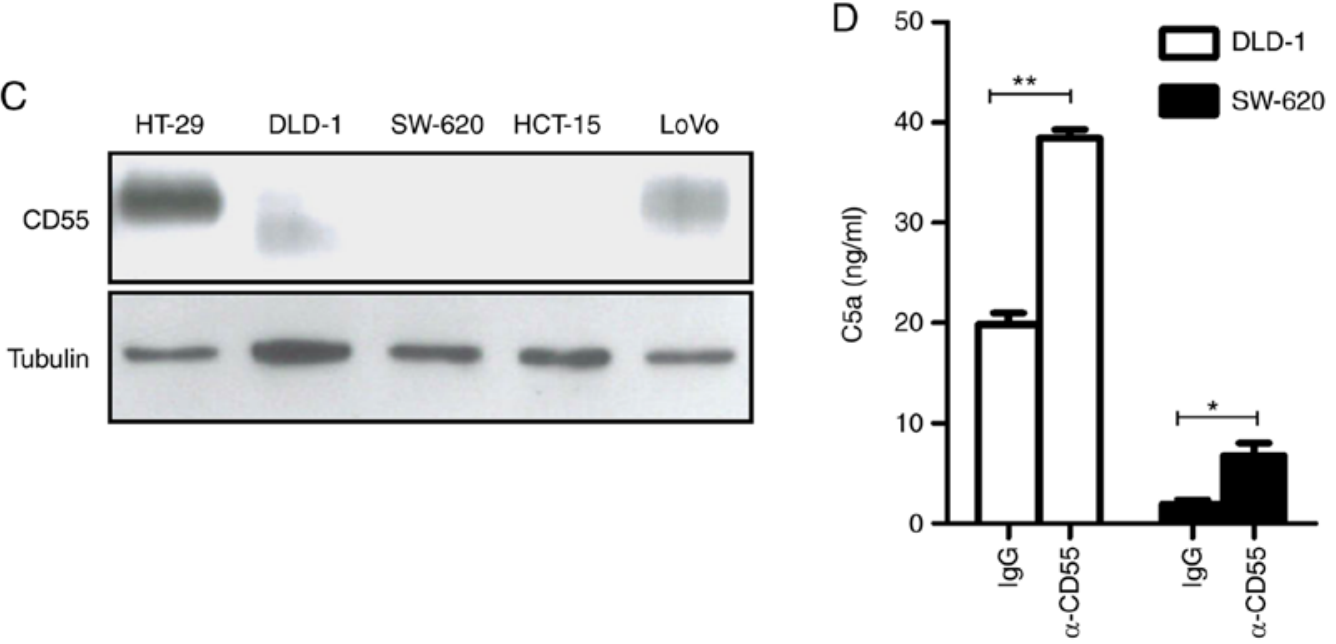

Figure 2. Validation of chimeric anti-CD55 monoclonal antibodies. (A) Representative flow cytometry analysis of CD55-positive HT-29 and CD55-negative SW-620 cells stained with the Ab1 anti-CD55 antibody. (B) Flow cytometric analysis of CD55-positive HT-29, DLD-1, and LoVo cells and CD55-negative SW-620 cells stained with the Ab1 anti-CD55 antibody. (C) Immunoblots of endogenous CD55 and tubulin in HT-29, DLD-1, SW-620, HCT-15 and LoVo cells. (D) Release of human C5a from DLD-1 and SW-620 cells. Cells were treated with human IgG or anti-CD55 antibody and released human C5a was measured in the cell supernatants by ELISA. The results are presented as the mean $\pm \operatorname{SEM}\left(n=3 ;{ }^{*} \mathrm{P}<0.05,{ }^{* *} \mathrm{P}<0.01\right.$, Student's $\mathrm{t}$ test).

referred to as 'anti-CD55 antibody') is a promising therapeutic candidate for treating colorectal cancer.

For application as a colorectal cancer therapy, the binding activity of anti-CD55 was analyzed in colorectal cancer cells expressing various levels of CD55: CD55-positive HT-29, DLD-1 and LoVo cells and CD55-negative SW-620 cells (Fig. 2B). The expression of CD55 in colorectal cancer cell lines was validated with a commercially available anti-CD55 antibody by immunoblotting. Different sizes of CD55 in DLD-1 cells might be caused by different glycosylation (Fig. 2C).

Next, it was confirmed whether the anti-CD55 antibody activates complement-dependent responses. Complement activity was measured by a product of the complement system, C5a, through an enzyme-linked immunosorbent assay
(ELISA). Indeed, a clear increase in C5a release was demonstrated after anti-CD55 antibody treatment (Fig. 2D). These findings demonstrate that the validated anti-CD55 antibody has the potential to treat colorectal cancer cells by activation of the complement system.

Therapeutic efficacy of the anti-CD55 antibody in colorectal cancer cells. The therapeutic effect of neutralizing antibody against CD55 was determined both in vitro and in vivo. The anti-CD55 antibody decreased the viability of HT-29 cells when the cells were treated with anti-CD55 antibody (Fig. 3A). Anti-CD55-treated HT-29 cells rounded up and detached, whereas IgG-treated cells remained normal in shape (flat and attached) (Fig. 3B). Consistent with the HT-29 cell results, 
A
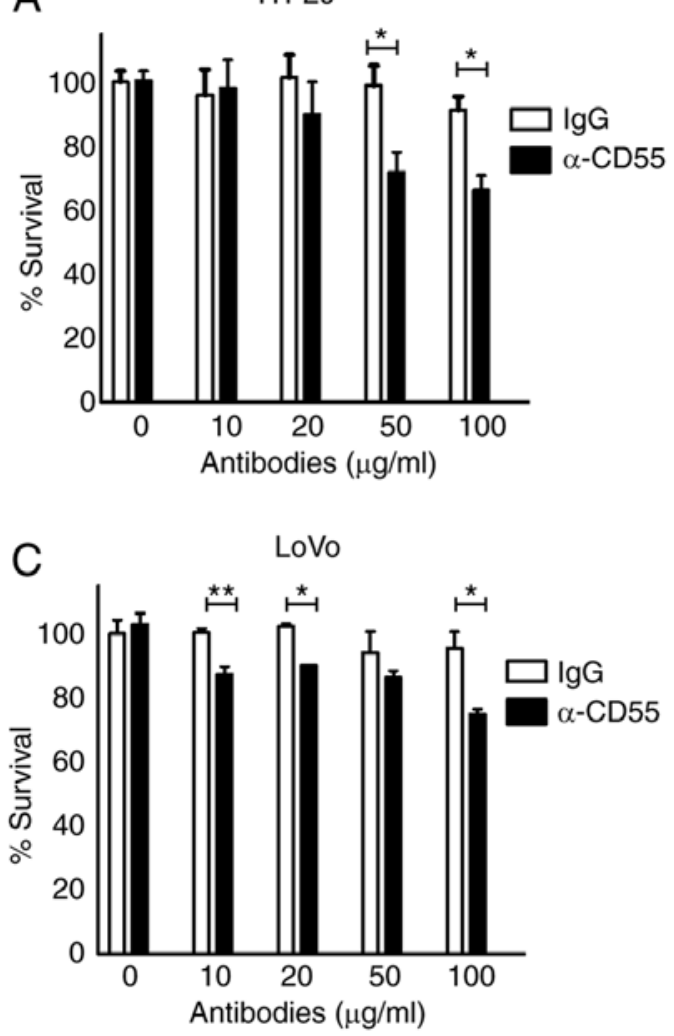

E

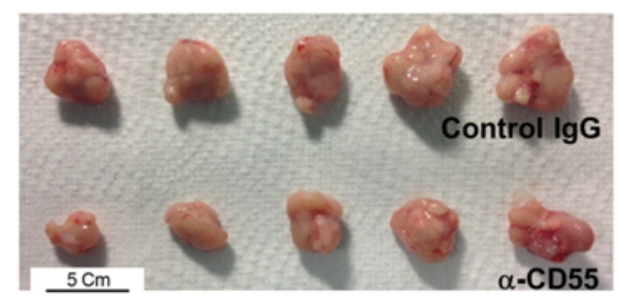

B
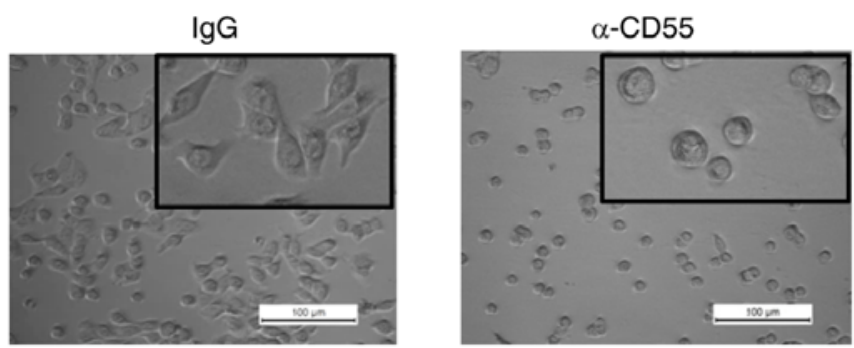

HT-29

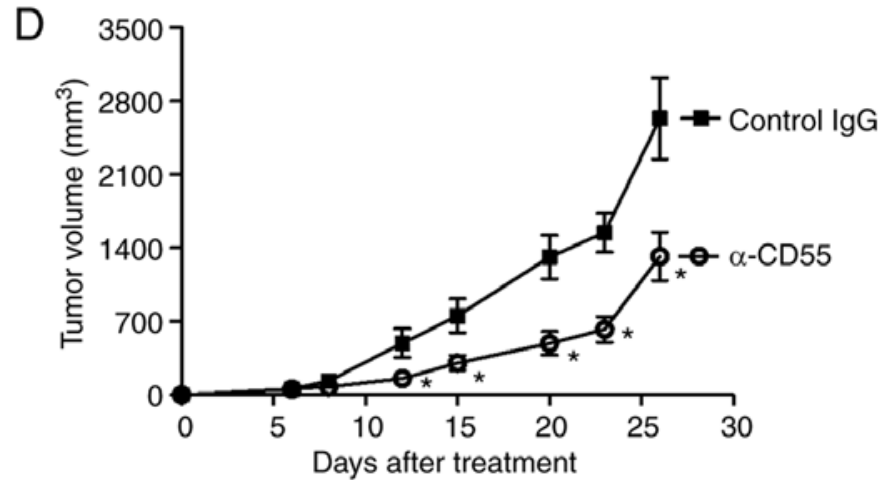

$\mathrm{F}$

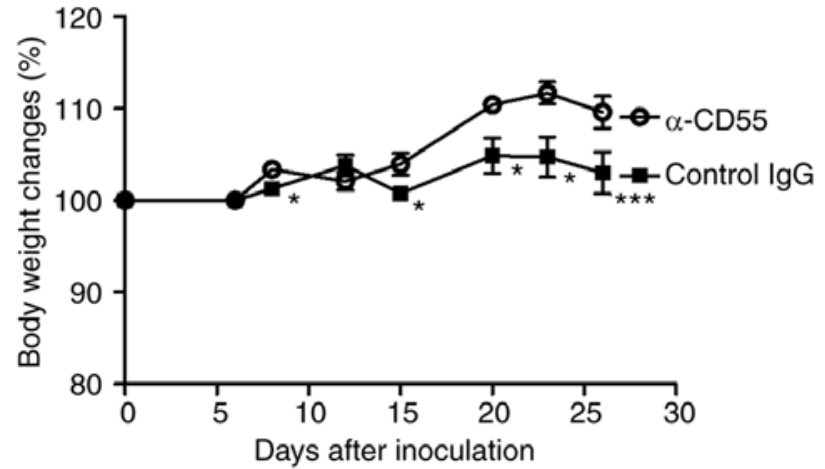

Figure 3. Effect of the anti-CD55 antibody on cell viability of colorectal cancer cells. (A) Cell viability assays of HT-29 colorectal cancer cells treated with IgG and anti-CD55. The results are presented as the mean $\pm \operatorname{SEM}\left(n=3\right.$; ${ }^{P}<0.05$, Student's $t$ test). (B) Representative microscopic images of HT-29 cells treated with $\mathrm{IgG}$ and anti-CD55. (C) Cell viability assays of LoVo colorectal cancer cells treated with IgG and anti-CD55. The results are presented as the mean \pm SEM $\left(\mathrm{n}=3 ;{ }^{*} \mathrm{P}<0.05,{ }^{* *} \mathrm{P}<0.01\right.$, Student's $\mathrm{t}$ test). (D) Effects of the anti-CD55 antibody on the survival of LoVo-bearing xenograft mice ( $\mathrm{n}=5$ for each group). The results are presented as the mean \pm SEM $($ ( $\mathrm{P}<0.05$, Student's $t$ test). (E) Tumors excised from xenograft mice treated with control or anti-CD55 antibodies at the end of the xenograft experiment. Scale bar, $5 \mathrm{~cm}$. (F) Effects of the anti-CD55 antibody on body weight changes (\%) in mice with LoVo-bearing xenograft mice. The results are presented as the mean $\pm \operatorname{SEM}\left(n=5 ;{ }^{*} \mathrm{P}<0.05,{ }^{* * *} \mathrm{P}<0.001\right.$, Student's $t$ test $)$.

anti-CD55 reduced the viability of LoVo cells by $25.1 \%$ (Fig. 3C).

Since LoVo cells contain mutations which may irritate the immune system, it was suspected that the anti-CD55 antibody may attenuate LoVo-bearing tumors. Importantly, LoVo-induced tumorigenesis and, consequently, tumor volume were significantly attenuated by treating LoVo-bearing xenograft mice with anti-CD55 antibody (Fig. 3D and E). Finally, to further examine the potential toxicity of anti-CD55 antibody, the body weight of IgG- and anti-CD55 antibody-treated mice was analyzed. LoVo-bearing xenograft mice tolerated treatment with the anti-CD55 antibody (Fig. 3F), suggesting that the toxicity of the anti-CD55 antibody was insignificant. Surprisingly, an increase in body weight was observed in anti-CD55 antibody-treated mice (Fig. 3F). Since cachexia and weight loss are problems among cancer patients, anti-CD55 would likely have a beneficial effect on quality of life.

The anti-metastatic effect of the anti-CD55 antibody in colorectal cancer cells. Even though the anti-CD55 antibody did not attenuate the viability of DLD-1 cells (Fig. S1), invasion and migration were significantly reduced in anti-CD55 antibody-treated DLD-1 cells (Fig. 4A). Therefore, anti-CD55 was able to inhibit metastasis at least in DLD-1 cells. Since an overexpression of CD55 was observed in metastatic liver and omentum tissues (Fig. 4Ba and Bb), CD55 induces metastasis at least in certain contexts of colorectal cancer tissues.

The possibility that anti-CD55 induces proinflammatory cytokines to prevent metastasis was assessed. The RT-qPCR analysis confirmed lipopolysaccharide-induced upregulation 
A
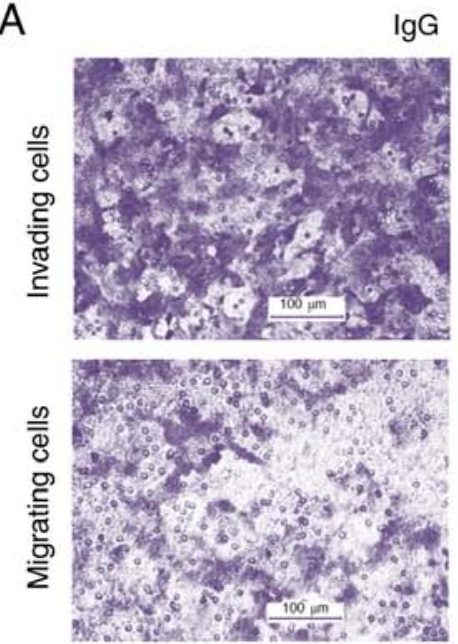

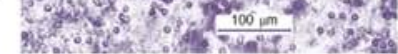

B

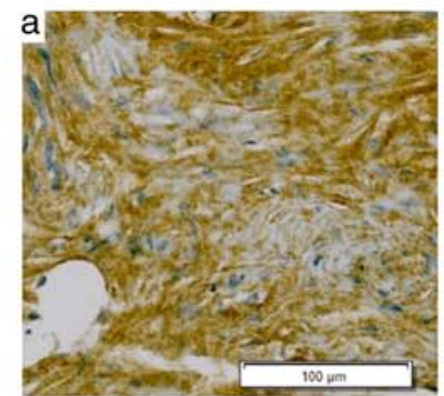

C

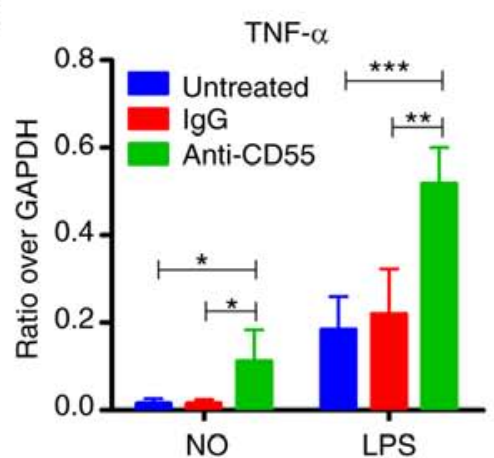

$\mathrm{IL}-1 \beta$

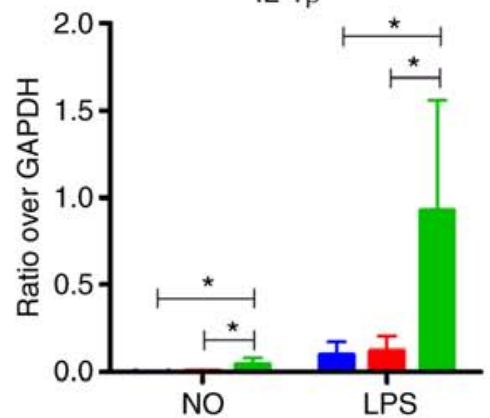

$\alpha-\operatorname{CD} 55$
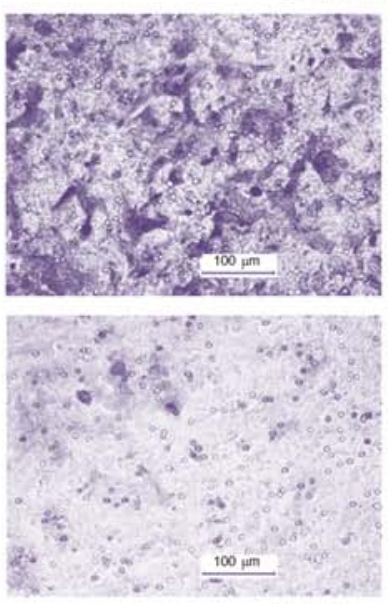

DLD-1

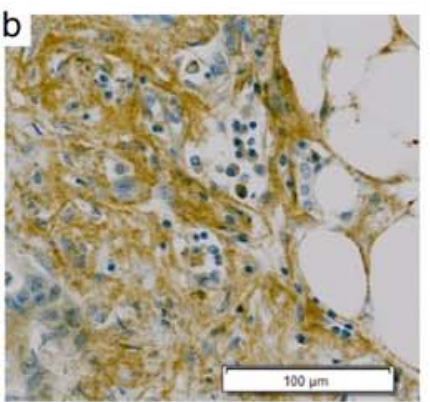

IL-6

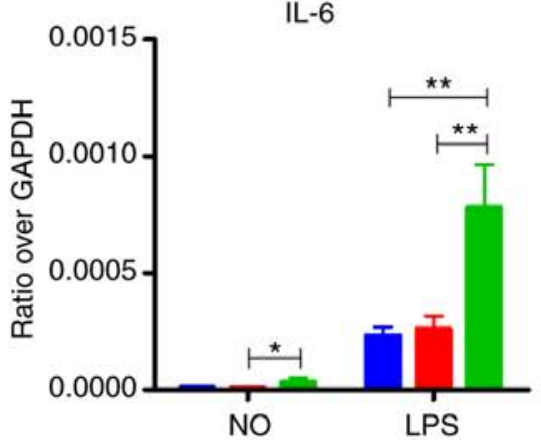

LPS
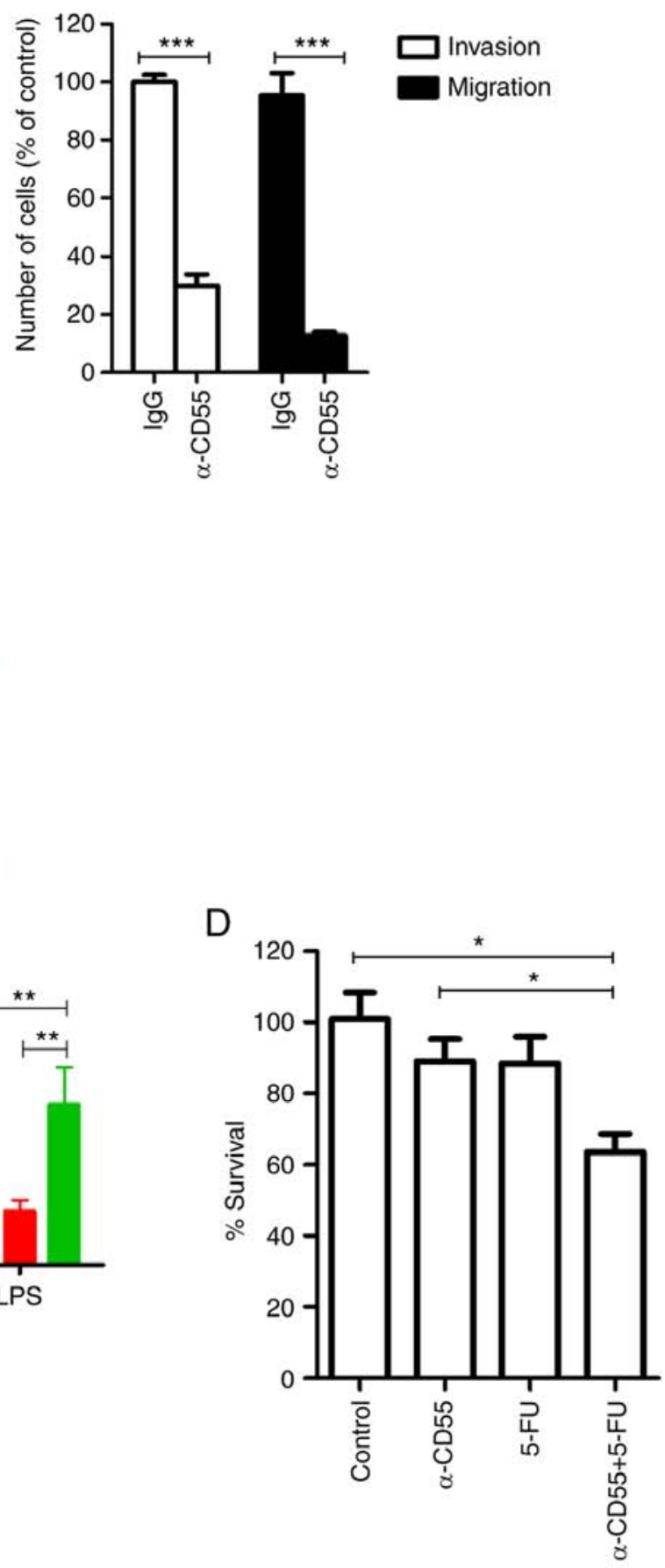

Figure 4. The effect of the anti-CD55 antibody on invasion and migration of colorectal cancer cells. (A) Invasion and migration of DLD-1 cells treated with $\mathrm{IgG}$ and the anti-CD55 antibody. The results are presented as the mean $\pm \mathrm{SEM}\left(\mathrm{n}=8 ;{ }^{* * *} \mathrm{P}<0.001\right.$, Student's $\mathrm{t}$ test). (B) Immunohistochemical analysis of CD55 in metastatic cancer tissues. (a) Metastatic liver tissue; (b) metastatic omentum tissue. Scale bars, $100 \mu \mathrm{m}$. (C) RT-qPCR of cytokines in THP-1 cells, including TNF- $\alpha$, IL-6, and IL-1 $\beta$. Cells were treated with LPS in the presence of IgG or anti-CD55. The results are presented as the mean \pm SEM ( $n=4$; ${ }^{*} \mathrm{P}<0.05$, ${ }^{* *} \mathrm{P}<0.01,{ }^{* * *} \mathrm{P}<0.001$, one-way ANOVA). (D) Cell viability assays of LoVo cells treated with anti-CD55 in the presence or absence of 5-FU. The results are presented as the mean \pm SEM $(n=3$; "P<0.05, one-way ANOVA). TNF- $\alpha$, tumor necrosis factor- $\alpha$; IL-6, interleukin- 6 ; IL-1 $\beta$, interleukin-1 $\beta$; 5-FU, 5 -fluorouracil.

of proinflammatory cytokine transcription in THP-1 cells by anti-CD55 antibody treatment (Fig. 4C). These findings suggest that the anti-CD55 antibody induces proinflammatory cytokine release and ultimately prevents metastasis. 
Enhanced antitumor effect of 5-FU in combination with the anti-CD55 antibody. The present findings suggest that anti-CD55 is able to enhance the antitumor efficacy of 5-FU. To examine the combinatorial efficacy of anti-CD55 and 5-FU, LoVo cells were treated with anti-CD55 antibody in the presence or absence of 5-FU. The combined treatment of anti-CD55 antibody and 5-FU led to a reduction in cell viability at all time points assessed (Fig. S2). At day 2, treatment of LoVo cells with either anti-CD55 or 5-FU alone decreased cell viability. A combinatorial treatment of these two agents diminished cell viability, which was indicative of a synergistic effect (Fig. 4D). Therefore, the anti-CD55 antibody demonstrated promising therapeutic effects in colorectal cancer and would be more curative as a combined therapy.

\section{Discussion}

The expression of CD55 and its clinical relevance in colorectal cancer have not yet been established. CD55 upregulation has been demonstrated in some colorectal cancers (24-26); however, several groups have reported that CD55 is not highly expressed in colorectal tumor tissues (12).

Herein, it is demonstrated that CD55 is overexpressed in subsets of colorectal cancer tissues and the novel anti-CD55 antibody suppresses colorectal tumorigenesis. The anti-CD55 antibody activated complement, stimulated the production of proinflammatory cytokines and ultimately caused cancer cell death. Considering that CD55 suppresses T cell immunity (27) and natural killer cells (28), the anti-CD55 antibody might activate both, thus impeding tumor initiation and growth Additionally, natural killer cell and/or macrophage-mediated antibody-dependent cell-mediated cytotoxicity might be expanded by the anti-CD55 antibody. Importantly, combinational therapy with the novel CD55 antibody with 5-FU enhanced the therapeutic effect against colorectal cancer. Interestingly, a previous study showed that neutralization of CD55 augments the therapeutic effect of Herceptin in lung carcinoma cells (29). Therefore combined therapy with the novel anti-CD55 antibody and Herceptin may also be an important strategy in lung cancer even if anti-CD55 antibody alone did not reduce the viability of H460 lung cancer cells (11).

In the immunohistochemistry assay, only 2 of 10 metastatic tissues were strongly positive for CD55, even given the limited sample size (Table SI). This finding was not expected since $51.2 \%$ of colorectal adenocarcinoma tissues were strongly positive for CD55. In contrast, it has been suggested that CD55 facilitates metastasis via CD97 binding and oncogenic tyrosine kinase pathways (28). Therefore, the possibility of anti-CD55 antibody affecting the metastasis of colorectal cancer cells was examined. Notably, whereas HT-29 and LoVo cells were not properly metastasized in the transwell assay, DLD-1 colorectal cancer cells migrated and invaded appropriately in the same system and it was revealed that the novel therapeutic anti-CD55 monoclonal antibody inhibits metastasis of colorectal cancer cells.

It has also been reported that the complement component C3, a downstream factor of CD55, facilitates leptomeningeal metastasis (30), suggesting that CD55 could also be used for therapy against this disease. These data suggest that the novel anti-CD55 antibody can be used to treat a broad range of tumors as both a monotherapy and a combination therapy.
Weight loss is one of the critical factors which determine quality of life for cancer patients since they suffer from cachexia and malnutrition, which lead to wasted energy with atrophy of fat and skeletal muscle (31). Therefore, considering the lack of weight loss due to anti-CD55 treatment (Fig. 3F), this antibody could be considered as a promising antineoplastic candidate able to minimize cancer patients' discomfort and extend their survival. Additionally, low kidney toxicity is crucial for cancer patients. The anti-CD55 monoclonal antibody was radiolabeled with ${ }^{177} \mathrm{Lu}$ to detect kidney deposition and the levels of ${ }^{177} \mathrm{Lu}$-anti-CD55 in the kidney were not high (2.79-6.19\% ID/g) (11). Efforts are being made to shorten the half-life of anti-CD55 antibody by Ab Fc engineering to minimize toxicity.

Interestingly, soluble CD55 is present in the stool of colorectal cancer patients, possibly mediated by metalloproteinase-7 (32). This suggests that CD55 may be used as a marker for colorectal cancer and that the anti-CD55 antibody could potentially be utilized for colorectal cancer diagnosis and therapeutics.

It has been reported that CD55 is associated with a number of diseases, including malaria (33), protein-losing enteropathy (34) and autoimmune diseases (35). Interestingly, targeting CD55 on erythrocytes would not cause substantial toxicity considering the existence of hematologically normal individuals lacking CD55 (33). Thus, the anti-CD55 antibody may be a promising vaccine or therapy, especially for malaria. Notably, eculizumab, a monoclonal antibody against $\mathrm{C} 5$ that inhibits terminal complement activation, has been used to treat paroxysmal nocturnal hemoglobinuria (36). Therefore, the anti-CD55 antibody might be a therapy for paroxysmal nocturnal hemoglobinuria because CD55 is another complement inhibitor.

\section{Acknowledgements}

Not applicable.

\section{Funding}

This work was supported by the Korea Atomic Energy Research Institute major project: Development of Radioisotope Production and Application Technology (grant no. 525330-18).

\section{Availability of data and materials}

The datasets used during the present study are available from the corresponding author upon reasonable request.

\section{Authors' contributions}

SHD, JCL and LKK designed the study and wrote the manuscript. SHD, EHC, JYL, SYL and SHJ planned and analyzed all experiments. JCL, SHJ and LKK supervised the study.

\section{Ethics approval and consent to participate}

Animal care and experimental protocols were approved by the Institutional Animal Care and Use Committee at Korea Atomic Energy Research Institue (KAERI) (KAERI-IACUC-2017-025). 


\section{Patient consent for publication}

Not applicable.

\section{Competing interests}

The authors state that they have no competing interests.

\section{References}

1. Ansell SM, Lesokhin AM, Borrello I, Halwani A, Scott EC, Gutierrez M, Schuster SJ, Millenson MM, Cattry D, Freeman GJ, et al: PD-1 blockade with nivolumab in relapsed or refractory Hodgkin's lymphoma. N Engl J Med 372: 311-319, 2015.

2. Garon EB, Rizvi NA, Hui R, Leighl N, Balmanoukian AS, Eder JP, Patnaik A, Aggarwal C, Gubens M, Horn L, et al: Pembrolizumab for the treatment of non-small-cell lung cancer. N Engl J Med 372: 2018-2028, 2015.

3. Macor P and Tedesco F: Complement as effector system in cancer immunotherapy. Immunol Lett 111: 6-13, 2007.

4. Pawluczkowycz AW, Beurskens FJ, Beum PV, Lindorfer MA, van de Winkel JG, Parren PW and Taylor RP: Binding of submaximal $\mathrm{Clq}$ promotes complement-dependent cytotoxicity (CDC) of B cells opsonized with anti-CD20 mAbs ofatumumab (OFA) or rituximab (RTX): Considerably higher levels of CDC are induced by OFA than by RTX. J Immunol 183: 749-758, 2009.

5. Meyer S, Leusen JH and Boross P: Regulation of complement and modulation of its activity in monoclonal antibody therapy of cancer. MAbs 6: 1133-1144, 2014.

6. Szebeni J, Alving CR, Savay S, Barenholz Y, Priev A, Danino D and Talmon Y: Formation of complement-activating particles in aqueous solutions of Taxol: Possible role in hypersensitivity reactions. Int Immunopharmacol 1: 721-735, 2001

7. Gilbert RD, Stanley LK, Fowler DJ, Angus EM, Hardy SA and Goodship TH: Cisplatin-induced haemolytic uraemic syndrome associated with a novel intronic mutation of CD46 treated with eculizumab. Clin Kidney J 6: 421-425, 2013.

8. Spendlove I, Ramage JM, Bradley R, Harris C and Durrant LG: Complement decay accelerating factor (DAF)/CD55 in cancer. Cancer Immunol Immunother 55: 987-995, 2006.

9. Li L, Spendlove I, Morgan J and Durrant LG: CD55 is over-expressed in the tumour environment. Br J Cancer 84: 80-86, 2001.

10. Durrant LG, Doran M, Austin EB and Robins RA: Induction of cellular immune responses by a murine monoclonal anti-idiotypic antibody recognizing the 791 Tgp72 antigen expressed on colorectal, gastric and ovarian human tumours. Int J Cancer 61: 62-66, 1995.

11. Dho SH, Kim SY, Chung C, Cho EH, Lee SY, Kim JY, Kim LK, Min SW, Lee J, Jung SH and Lim JC: Development of a radionuclide-labeled monoclonal anti-CD55 antibody with theranostic potential in pleural metastatic lung cancer. Sci Rep 8: 8960, 2018

12. Thorsteinsson L, O'Dowd GM, Harrington PM and Johnson PM: The complement regulatory proteins CD46 and CD59, but not CD55, are highly expressed by glandular epithelium of human breast and colorectal tumour tissues. APMIS 106: 869-878, 1998

13. Marisa L, de Reyniès A, Duval A, Selves J, Gaub MP, Vescovo L, Etienne-Grimaldi MC, Schiappa R, Guenot D, Ayadi M, et al: Gene expression classification of colon cancer into molecular subtypes: Characterization, validation, and prognostic value. PLoS Med 10: e1001453, 2013.

14. Timmermann B,Kerick M, RoehrC, Fischer A, Isau M, Boerno ST, Wunderlich A, Barmeyer C, Seemann P, Koenig J, et al: Somatic mutation profiles of MSI and MSS colorectal cancer identified by whole exome next generation sequencing and bioinformatics analysis. PLoS One 5: e15661, 2010.

15. Le DT, Uram JN, Wang H, Bartlett BR, Kemberling $H$, Eyring AD, Skora AD, Luber BS, Azad NS, Laheru D, et al: PD-1 blockade in tumors with mismatch-repair deficiency. N Engl J Med 372: 2509-2520, 2015.

16. Topalian SL, Hodi FS, Brahmer JR, Gettinger SN, Smith DC, McDermott DF, Powderly JD, Carvajal RD, Sosman JA Atkins MB, et al: Safety, activity, and immune correlates of anti-PD-1 antibody in cancer. N Engl J Med 366: 2443-2454, 2012.
17. Gustavsson B, Carlsson G, Machover D, Petrelli N, Roth A, Schmoll HJ, Tveit KM and Gibson F: A review of the evolution of systemic chemotherapy in the management of colorectal cancer. Clin Colorectal Cancer 14: 1-10, 2015

18. Russo A, Maiolino S, Pagliara V, Ungaro F, Tatangelo F, Leone A, Scalia G, Budillon A, Quaglia F and Russo G: Enhancement of 5-FU sensitivity by the proapoptotic rpL3 gene in p53 null colon cancer cells through combined polymer nanoparticles. Oncotarget 7: 79670-79687, 2016.

19. Modest DP, Neumann UP and Pratschke J: FOLFOXIRI plus bevacizumab as conversion-therapy for liver metastases in colorectal cancer: A necessity? Eur J Cancer 73: 71-73, 2017.

20. Launay M, Dahan L, Duval M, Rodallec A, Milano G, Duluc M, Lacarelle B, Ciccolini J and Seitz JF: Beating the odds: Efficacy and toxicity of dihydropyrimidine dehydrogenase-driven adaptive dosing of 5-FU in patients with digestive cancer. $\mathrm{Br} \mathrm{J}$ Clin Pharmacol 81: 124-130, 2016.

21. Bamford S, Dawson E, Forbes S, Clements J, Pettett R, Dogan A, Flanagan A, Teague J, Futreal PA, Stratton MR and Wooster R: The COSMIC (Catalogue of Somatic Mutations in Cancer) database and website. Br J Cancer 91: 355-358, 2004.

22. Shin G, Kang TW, Yang S, Baek SJ, Jeong YS and Kim SY: GENT: Gene expression database of normal and tumor tissues. Cancer Inform 10: 149-157, 2011

23. Kim HY: Analysis of variance (ANOVA) comparing means of more than two groups. Restor Dent Endod 39: 74-77, 2014.

24. Nakagawa M, Mizuno M, Kawada M, Uesu T, Nasu J, Takeuchi K, Okada H, Endo Y, Fujita T and Tsuji T: Polymorphic expression of decay-accelerating factor in human colorectal cancer. J Gastroenterol Hepatol 16: 184-189, 2001.

25. Koretz K, Brüderlein S,Henne C and Möller P:Decay-accelerating factor (DAF, CD55) in normal colorectal mucosa, adenomas and carcinomas. Br J Cancer 66: 810-814, 1992.

26. Niehans GA, Cherwitz DL, Staley NA, Knapp DJ and Dalmasso AP: Human carcinomas variably express the complement inhibitory proteins CD46 (membrane cofactor protein), CD55 (decay-accelerating factor), and CD59 (protectin), Am J Pathol 149: 129-142, 1996.

27. Liu J, Miwa T, Hilliard B, Chen Y, Lambris JD, Wells AD and Song WC: The complement inhibitory protein DAF (CD55) suppresses T cell immunity in vivo. J Exp Med 201: 567-577, 2005.

28. Mikesch JH, Schier K, Roetger A, Simon R, Buerger H and Brandt $\mathrm{B}$ : The expression and action of decay-accelerating factor (CD55) in human malignancies and cancer therapy. Cell Oncol 28: 223-232, 2006.

29. Zhao WP, Zhu B, Duan YZ and Chen ZT: Neutralization of complement regulatory proteins CD55 and CD59 augments therapeutic effect of herceptin against lung carcinoma cells. Oncol Rep 21: 1405-1411, 2009.

30. Boire A, Zou Y, Shieh J, Macalinao DG, Pentsova E and Massagué J: Complement component 3 adapts the cerebrospinal fluid for leptomeningeal metastasis. Cell 168: 1101.e13-1113.e13, 2017.

31. Kir S, White JP, Kleiner S, Kazak L, Cohen P, Baracos VE and Spiegelman BM: Tumour-derived PTH-related protein triggers adipose tissue browning and cancer cachexia. Nature 513: 100-104, 2014.

32. Morgan J, Spendlove I and Durrant LG: The role of CD55 in protecting the tumour environment from complement attack. Tissue Antigens 60: 213-223, 2002.

33. Egan ES, Jiang RH, Moechtar MA, Barteneva NS, Weekes MP, Nobre LV, Gygi SP, Paulo JA, Frantzreb C, Tani Y, et al: Malaria. A forward genetic screen identifies erythrocyte CD55 as essential for Plasmodium falciparum invasion. Science 348: 711-714, 2015.

34. Ozen A, Comrie WA, Ardy RC, Domínguez Conde C, Dalgic B, Beser ÖF, Morawski AR, Karakoc-Aydiner E, Tutar E, Baris S, et al: CD55 deficiency, early-onset protein-losing enteropathy, and thrombosis. N Engl J Med 377: 52-61, 2017.

35. Visser L, de Vos AF, Hamann J, Melief MJ, van Meurs M, van Lier RA, Laman JD and Hintzen RQ: Expression of the EGF-TM7 receptor CD97 and its ligand CD55 (DAF) in multiple sclerosis. J Neuroimmunol 132: 156-163, 2002.

36. Hillmen P, Young NS, Schubert J, Brodsky RA, Socié G, Muus P, Röth A, Szer J, Elebute MO, Nakamura R, et al: The complement inhibitor eculizumab in paroxysmal nocturnal hemoglobinuria. N Engl J Med 355: 1233-1243, 2006. 